expectations of fifty years. It is also based on the view that the need for research, and the understanding of that need, are likely to grow beyond our present computations. This view takes into account two lessons of the war period. One is that horticulture has changed from an incidental luxury into a necessary part of the nation's economy. The other is that genetics has changed from an ornament of research to one of the main props of science.

In its new habitation, the John Innes Institution will undoubtedly undergo a transformation. But there seems no reason why it should forsake the character or the aim for which it has been valued. Its aim will no doubt continue to be to unite theory with practice and to combine a freedom of initiative with some coherence of purpose within the wide range of activities allowed by its foundation.

\section{THE TEACHING OF ANALYTICAL CHEMISTRY IN GREAT BRITAIN : WITH SPECIAL REFERENCE TO MICROCHEMISTRY}

\section{BY DR. CECIL L. WILSON}

$\mathrm{F}^{\mathrm{o}}$ OR some time past it has not been possible to make any accurate estimate of how the demand for microchemical teaching in the British Isles has been met. Previously, the only guide in this direction was the list, probably not altogether comprehensive, published from time to time in Mikrochemie before the War. As a consequence, discussion of the teaching of microchemistry must of necessity have been based largely on estimates derived solely from personal contacts and hearsay, and any statement about it was justly open to doubt.

The only satisfactory way to clear up the position was by means of some sort of census. This was scarcely an undertaking for a private individual. The recent formation of the Microchemistry Group of the Society of Public Analysts and Other Analytical Chemists, however, provided an official body to which the information is of first importance. At the request of the Committee of this Group (under the chairmanship of Prof. H. V. A. Briscoe, Imperial College of Science and Technology, London), therefore, a questionnaire was drawn up, the answers to which would clarify the position of the teaching of modern analytical methods, and, in particular, of microchemistry. This questionnaire has been circulated to 85 centres of higher chemical education in the British Isles, comprising 43 universities, university colleges and university institutes, and 42 technical institutions. Replies have been received from 64 of the institutions -75 per cent of the total covered-made up of 32 universities and their institutes and 32 technical colleges. The information contained in the replies has been collated, and forms the basis of this report.

It was difficult to draw up a questionnaire which would cover the situation both completely and in detail. In fact, study of the replies suggests that such an achievement would have been impossible. But it must be acknowledged that most of the institutions received the questionnaire in an extremely helpful spirit, and did their best to interpret doubtful questions so as to supply the maximum of useful information. Many institutions made valuable additional comments, and it is perhaps in these that most food for thought will be found.
In spite of this co-operation, some points were missed completely, while others still remain vague. For example, as was pointed out in one reply, one question which should have been asked, and was not, concerned the number of microchemical balances possessed by each institution. Answers to this might conceivably have been useful in clearing up certain vagueness in other replies. Again, confusion in nomenclature, more particularly as between the terms 'micro' and 'semi-micro', is apparent; while some institutions probably put a much wider interpretation than was intended on a question which asked for information about special courses dealing with modern analytical techniques. This gives rise to doubts as to whether the teaching of any of the more modern techniques is really as advanced. as is suggested by a superficial study of the replies.

As a consequence, it has been necessary, in reporting, to interpret equally broadly on occasion. But it is felt that, at least so far as microchemistry is concerned, this summary presents a much more coherent and truthful picture than has hitherto boen available. Where it has been thought desirable, distinction has been made between the technical colleges and the universities, as the conditions ruling in each of these groups, and controlling their activities, are markedly different in many ways.

\section{Modern Analytical Methods}

Of the 64 institutions replying, 25 normally teach electrochemical analysis, 16 teach spectrographic analysis, and 25 teach electrometric methods. One or two of these courses of instruction have been interrupted owing to the War. In addition, 5 institutions teach the use of the polarograph, 12 colorimetry photometry, 2 metallurgical analysis, and 10 report miscellaneous or unspecified courses.

It is probable, as already suggested, that in many cases this instruction merely forms part of an existing course in general chemistry, and is not a special course. There are, however, certain institutions the replies from which indicate clearly that in their case the courses are special ones dealing only with the methods specified, in a reasonably detailed fashion.

Only 3 of the institutions replying possess a special lectureship in analytical chemistry. However, 12 other institutions find it necessary to qualify the negative reply by stating either that they have a lecturer concerned solely or almost solely with this branch of work, or that such a lectureship is desirable or projected.

\section{Microchemistry}

In all, 43 of the institutions, that is, almost 70 per cent, have taught or teach microchemistry in some form or another.

The first course in microchemistry in Britain appears to have been established in 1929. Of the 20 institutions which give a date for the commencement of their course or courses, 16 started prior to the War, only 4 since. This is quite to be expected. The peak years for new courses were around 1936-38.

Estimates were given by 22 institutions of the time spent on micro work. These estimates range, rather startlingly, from 4 hours per student to 300 hours. Examining these figures rather more closely, an average value for the 22 institutions is just over 65 hours per student. Of the individual estimates, 6 lie above the 100-hour mark, and 12 above 50 hours. Rather surprisingly, these figures are distributed fairly equally between universities and technical colleges. 
In Table 1, which indicates roughly the grading of the courses, those referred to as "current" are running at present. Those designated "pre-war" were in existence before the War, but have since been suspended. Thus the total of these two gives some measure of the probable minimum number of courses which would be in existence at present, had it not been for the War.

\begin{tabular}{|c|c|c|c|c|}
\hline & & $\begin{array}{l}\text { IIX } 1 . \\
\text { Universities }\end{array}$ & $\begin{array}{c}\text { Technical } \\
\text { Colleges }\end{array}$ & \\
\hline $\begin{array}{l}\text { Special Postgraduate } \\
\text { Current }\end{array}$ & Courses: & & & \\
\hline $\begin{array}{l}\text { Current ... } \\
\text { Pre-war ... }\end{array}$ & .. & 4 & $\begin{array}{l}3 \\
5\end{array}$ & \\
\hline \multirow{2}{*}{\multicolumn{5}{|c|}{ 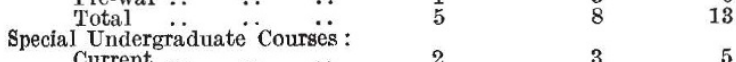 }} \\
\hline & & & & \\
\hline $\begin{array}{l}\text { Current } \\
\text { Pre-war }\end{array}$ & $\because$ & $\begin{array}{l}2 \\
1\end{array}$ & $\begin{array}{l}3 \\
1\end{array}$ & \\
\hline \multirow{2}{*}{\multicolumn{2}{|c|}{$\begin{array}{l}\text { Routine Instruction to Under- } \\
\text { graduates: }\end{array}$}} & 3 & 4 & \\
\hline & .. & 11 & 10 & \\
\hline Pre-war .. & .. & ${ }_{17}^{6}$ & 5 & 1 \\
\hline Total & & & & \\
\hline
\end{tabular}

As this shows, of 64 institutions, there should be, after the War, at least 52 potential courses in the practice of some form of micro methods-25 in universities, and 27 in technical colleges. In fact, this figure is almost certainly an under-estimate, as several institutions report projected courses, not included in Table 1, which have not yet materialized because of the War.

The outstanding point that is brought out here, however, is the impressive number of institutions50 per cent- - which have found it advisable to introduce microchemistry to some extent as routine practice for students. This is concrete proof-perhaps the first to be produced-of the appeal and usefulness of micro methods in teaching in Britain. It gives every justification for the recognition of these methods by examining bodies which control external examinations, thus enabling those institutions which teach for such examinations to do so on an equal footing with those which include microchemistry in courses for internal examinations, and with an equal claim to modernity.

Further details of the type of instruction are tabluated in Table 2 :

\begin{tabular}{|c|c|c|c|}
\hline \multicolumn{4}{|c|}{ TABIE 2.} \\
\hline & Universities & Colleges & Total \\
\hline Quantitative Organic Analysis & 13 & 15 & 28 \\
\hline Qualitative Inorganic Analysis & 9 & 18 & 27 \\
\hline Quantitative Inorganic Analysis & 10 & 11 & 21 \\
\hline Physicochemical Methods & 8 & 9 & 17 \\
\hline Synthetic Organic Methods & 7 & 9 & 16 \\
\hline Qualitative Organic Analysis & 5 & 7 & 12 \\
\hline Chemical Microscopy .. .. & 4 & $\dot{2}$ & 6 \\
\hline
\end{tabular}

Semi-micro methods are taught, either in conjunction with, or as an alternative to, full micro methods (it is not always clear which) as shown in Table 3 .

TABLE 3.

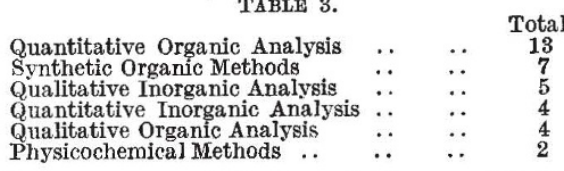

In the case particularly of the qualitative and synthetic methods, there seems to be considerable confusion over a distinction between the two seales of 'micro' and 'semi-micro'.

In preparing a general report such as this, it is almost impossible to give any closer indication of the type of instruction which prevails. It is felt, however, that it would be of interest to detail the instruction given at one institution, of moderate size, serving a town of average population (about 50,000-60,000). This institution, one of the more advanced in this respect, is not, however, necessarily the best. It is chosen rather as showing what can be undertaken by an institution which has only average resources of space, staff and finance, where the will to progress is present. Special courses deal with electrochemical analysis, electrometric methods of analysis, including the use of the "magic eye" apparatus, and absorptiometry. In general analytical chemistry, apparently a special postgraduate course, the following are dealt with : application of organic reagents to inorganic analysis ; chromatography; polarography; the electrograph ; use of luminescent, redox, adsorption and complex-forming indicators; the high-temperature combustion furnace; survey of the branches of microchemistry, etc. Coming to microchemical courses, these are held both as special undergraduate courses and as part of routine instruction to students. The branches covered include qualitative inorganic analysis, qualitative organic analysis, quantitative organic analysis, physicochemical measurements; synthetic organic methods are to be introduced soon, and quantitative inorganic analysis is taught on the semi-micro scale. The special course occupies two hours per week for its duration. The special remarks section states: "We are teaching micro-methods to National Certificate Students. A special course for final students and graduates is run in the Summer Vacation. It is hoped to extend it to 'outside' people this year".

The reasons given for absence of any, or of fuller, instruction in the various institutions occur in the following order of importance : lack of time (25); lack of staff with the appropriate 'knowledge (16); the War (14); lack of space (14) ; lack of apparatus (13); small educational value and limited uses of microchemistry (6). Certain of the answers-lack of staff, lack of space, lack of apparatus-are in some cases qualified by "during the War", these necessities having been loaned for national use.

The last category-small educational value and limited uses - must be read with some reserve, since of the 6 institutions putting it forward, 2 already teach some microchemistry, and 2 others propose introducing some after war conditions have eased.

As already remarked, the additional comments kindly supplied by the different institutions provide much that is of interest. The more important issues which they raise are best illustrated by quotation. Two divergent views of the value of microchemical instruction provide a striking assessment when taken in conjunction: "From educational standpoint, favour Inorganic micro in Third Year". "Micro and semi-micro technique is not taught for its own sake, but merely to improve the experimental technique of the students-mostly with a view to the saving of time". On the other hand, it is stated, "Many of our research investigations demand a good working knowledge of microchemistry in all its branches". "In chemical practice one so frequently has to deal with small quantities". In other words, microchemistry has proved its usefulness, whether it is considered solely as a teaching method or as an analytical tool.

A few of the institutions which already include some microchemical teaching doubt the wisdom of introducing more; but a considerable majority intend to increase substantially the time devoted to the subject when conditions permit.

The low regard in which analytical chemistry tends to be held is specially commented on by several writers : "Modern analytical methods should figure 
much more prominently in the curriculum of a Technical College than is customary at present". "Academic Institutions tend not to give much attention to chemical analysis. It is often quite difficult to make students do any accurate work".

Pleas are made for the provision of teaching for the teacher. "Vocational courses held at some suitable centre, for the training of teachers in the various branches of microchemical analysis, would be much appreciated". "It is desirable that a summer school for teachers should be established so that they may acquire a first-hand knowledge of the technique required. Prior to the War, such training was difficult to obtain in the British Isles".

The difficulty of the external examination is pointed out: "The chief determining factor is undoubtedly that the University of London and professional bodies generally do not yet demand a knowledge of microchemical technique in their practical examinations". "Omitted of late, since students have to complete their studies in less time than before" ; that is, discarded as the first inessential for examinations !

Finally, one comment may be coupled with the difficulties of those who plead lack of apparatus : "For quite a year now we have been unable to do micro organic analysis for research purposes, on account of the balances needing attention. It has not been possible to get even one of the three balances reconditioned".

Without further comment, it may be claimed that a number of conclusions are implicit in this survey. In the first place, there is undoubtedly a general recognition among teachers of the importance of analytical chemistry in general, and microchemical methods have obviously recommended themselves strongly to teachers as a useful instructional topic. Recognition of this by the professional and other examining bodies is desirable, particularly in view of the probable post-war development. Every effort ought to be made to secure this recognition, and to make possible further development of the regard for analytical chemistry in teaching institutions.

In this connexion it is perhaps worthy of stress that the size of the institution and the importance of the area which it serves seem to bear no direct relationship to its attitude to analytical and micro methods. In other words, small institutions are as advanced in this respect as larger ones, whether one considers the apparatus available or the nature and extent of the instruction. Presumably, therefore, development in analytical and microchemical teaching may be regarded as a function of individual endeavour, and further improvement in this respect is not altogether dependent on such physical factors as available funds.

Some provision should obviously be made for refresher courses in analytical chemistry of varying scope, arranged primarily, but not necessarily solely, for the benefit of teachers. It is out of the question for Britain to regress, in the next few years, to the pre-war condition of being almost entirely dependent on Central Europe for such a prime necessity.

In conclusion, it may be claimed that a subject which is regarded by 50 per cent of the more important teaching institutions of the British Isles as worth teaching cannot in future be considered to be beneath the notice of the chemist in general.

It is impossible to thank personally all those teachers who took pains to fill up the questionnaire, and to supply valuable further information. Grateful a.cknowledgment of their help is therefore made here.

\section{NEW BASIC CONCEPTS IN ELECTROCARDIOGRAPHY : THE VENTRICULAR GRADIENT}

\author{
By DR. W. F. BERG*
}

$\mathrm{C}$

LINICAL, anatomical and experimental research have all collaborated to make electrocardiography indispensable for the clinician. The nature and origin of the various irregularities of the heart rhythm can be diagnosed with accuracy. Since chest leads have been introduced, one can get detailed diagnoses of heart muscle lesions, such as result from an occlusion of the arteries supplying the heart muscle. Similarly, we are able to locate lesions within the specific nervous system of the heart known as the bundle of His and its branches. It is even possible to diagnose toxic changes so small as to escape the methods of the pathologist. An important advance has more recently been achieved by the introduction of a new basic concept by the American workers, F. N. Wilson ${ }^{1}$ and his school. This has found almost immediate practical application.

In the state of rest the heart, in common with all muscles, consists of polarized cells : the insides of the cells carry electric charges which are neutralized by charges of opposite sign surrounding the cells. The regular excitation and relaxation causes a rhythmic sequence of waves of electric depolarization and repolarization to pass through the heart muscle. Thus, at any one moment potential differences are set up between two points of the body; these can be measured by any instrument which is sufficiently sensitive. At any one instant the heart may be likened to an electric battery, the poles of which are inserted into a conducting medium, the body; such an arrangement is characterized by the direction of a line pointing, say, from the negative to the positive pole, and by the strength of the poles. Thus the electric excitation of the heart muscle is best described by an arrow possessing both a direction and a length ; this arrow is known as the instantaneous electric axis or heart vector. In order to determine this vector the following assumptions are commonly made.

In the standard procedure the current produced by the heart is recorded by an instrument of short period such as a string galvanometer or cathode ray tube, which is connected in turn to two out of three points : the left arm (L.A.), the right arm (R.A.) and the left leg (L.L.). Electrically the heart is considered to lie in the centre of an equilateral triangle, which is large compared with the dimensions of the heart and which is named after Einthoven. Records obtained simultaneously in two 'leads', say between the left and right arms, and the left arm and leg enable the instantaneous heart vector to be determined by the construction indicated in Fig. 1. The method is based on the consideration that the deflexion of the instrument in one lead is proportional to the projection of the heart voltage on to a straight line connecting the end points of that lead. Thus the deflexion in each lead at any one instant is the component of the vector in the direction of the lead line as marked inside the triangle. Verticals are erected at the end point of each component on a lead line. A line drawn from the centre of the triangle to the point where the verticals from two components cross constitutes the instantaneous vector. If deflexions are obtained in three leads simultaneously,

* From the CentralMiddlesex County Hospital, London. 